\title{
Mechanistic Analysis of Gold(I)-Catalyzed Intramolecular Allene Hydroalkoxylation Reveals an Off-Cycle Bis(gold) Vinyl Species and Reversible C-O Bond Formation
}

\author{
Timothy J. Brown ${ }^{\dagger}$, Dieter Weber ${ }^{\ddagger}$, Michel R. Gagné ${ }^{\star}, \ddagger$, and Ross A. Widenhoefer ${ }^{\star}, \dagger$ \\ †French Family Science Center, Duke University, Durham, North Carolina 27708-0346, United \\ States \\ ‡Caudill Laboratories, Department of Chemistry, University of North Carolina, Chapel Hill, North \\ Carolina 27599-3290, United States
}

\begin{abstract}
Mechanistic investigation of gold(I)-catalyzed intramolecular allene hydroalkoxylation established a mechanism involving rapid and reversible $\mathrm{C}-\mathrm{O}$ bond formation followed by turnover-limiting protodeauration from a mono(gold) vinyl complex. This on-cycle pathway competes with catalyst aggregation and formation of an off-cycle bis(gold) vinyl complex.
\end{abstract}

Over the past decade, the applications of soluble gold(I) complexes as catalysts for organic transformations, in particular the electrophilic activation of $\mathrm{C}-\mathrm{C}$ multiple bonds, have increased dramatically. ${ }^{1}$ In contrast to the extensive development of the synthetic aspects of gold(I) $\pi$-activation catalysis, the mechanisms of these transformations remain poorly defined and are derived largely from computational analyses. ${ }^{2}$ However, experimental evidence pertaining to the mechanisms of gold(I) $\pi$-activation catalysis, notably the in situ detection and/or independent synthesis of potential catalytic intermediates, has begun to emerge. ${ }^{3-5}$ Perhaps most intriguing among these potential intermediates are the bis(gold) vinyl complexes formed via the addition of nucleophiles to allenes or alkynes in the presence of gold(I) ${ }^{5,6}$ However, the extent to which formation of bis(gold) species represents a general phenomenon in gold $\pi$-activation catalysis remains unclear and lacking is information regarding the behavior of bis(gold) vinyl species vis-à-vis mono(gold) vinyl complexes ${ }^{4}$ under catalytic conditions.

Herein, we report the mechanistic investigation of the gold(I)-catalyzed intramolecular hydroalkoxylation of 2,2-diphenyl-4,5-hexadien-1-ol (1) to form 2-vinyltetrahydrofuran 2 (eq 1), ${ }^{7}$ which represents the first mechanistic analysis of

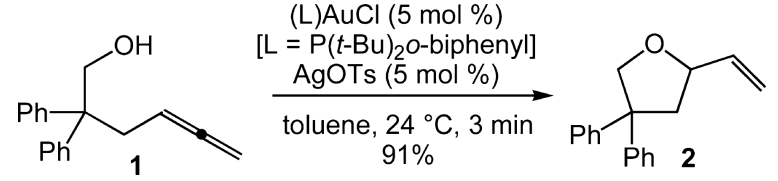

(C) 2012 American Chemical Society

*Corresponding Authorrwidenho@chem.duke.edu; mgagne@unc.edu.

Supporting Information Experimental procedures and kinetic, spectroscopic, and X-ray crystallographic data. This material is available free of charge via the Internet at http://pubs.acs.org.

The authors declare no competing financial interest. 
gold-catalyzed hydroalkoxylation. Importantly, this investigation delineates the catalytic behavior and interplay of the mono(gold) and bis(gold) vinyl complexes generated under catalytic conditions and establishes the reversibility of $\mathrm{C}-\mathrm{O}$ bond formation. ${ }^{8-10}$

In an effort to intercept gold vinyl intermediates in the gold(I)-catalyzed conversion of $\mathbf{1}$ to 2, a toluene suspension of $\mathbf{1},(\mathrm{L}) \mathrm{AuCl}\left[\mathrm{L}=\mathrm{P}(t-\mathrm{Bu})_{2} o\right.$-biphenyl], AgOTs, and $\mathrm{Et}_{3} \mathrm{~N}(1: 1: 1: 2)$ was stirred at room temperature for $1.5 \mathrm{~h}$ (Scheme 1). ${ }^{11}$ Aqueous workup and crystallization from warm hexanes gave mono(gold) vinyl complex 3 in $87 \%$ yield as an air- and thermally stable white solid that was fully characterized by spectroscopy and X-ray crystallography (Figure 1). Treatment of $\mathbf{3}\left(31 \mathrm{mM}\right.$ ) with (L)AuOTs (1 equiv) in $\mathrm{CD}_{2} \mathrm{Cl}_{2}$ at $0{ }^{\circ} \mathrm{C}$ led to immediate ( $5 \mathrm{~min}$ ) formation of the bis(gold) vinyl complex 4 in $98 \pm 5 \%$ yield by ${ }^{1} \mathrm{H}$ NMR (Scheme 1). Complex 4 persisted indefinitely in solution at this temperature but decomposed when concentrated and was therefore characterized in solution. Notably, the ${ }^{31} \mathrm{P}$ NMR spectrum of $\mathbf{4}$ displayed a 1:1 ratio of resonances at $\delta 61.7$ and 60.9, which established the presence of chemically inequivalent (L)Au fragments, while the large difference in the ${ }^{1} \mathrm{H}$ NMR shifts of the vinylic protons of 4 [ $\delta 4.84$ and 3.90] relative to those of $\mathbf{3}$ [ $\delta 5.48$ and 4.45] established interaction of the vinyl moiety of $\mathbf{4}$ with both (L) $\mathrm{Au}^{+}$fragments.

To evaluate the relevance of vinyl gold complexes $\mathbf{3}$ and $\mathbf{4}$ in the gold-catalyzed conversion of $\mathbf{1}$ to $\mathbf{2}$, we investigated the reaction of $\mathbf{1}$ with (L)AuOTs under stoichiometric and catalytic conditions. Reaction of a equimolar solution of $\mathbf{1}(55 \mathrm{mM})$ and (L)AuOTs in $\mathrm{CD}_{2} \mathrm{Cl}_{2}$ at $-80{ }^{\circ} \mathrm{C}$ led to immediate ( $₫ 10 \mathrm{~min}$ ) formation of a 1:1 mixture of $\mathbf{1}$ and $\mathbf{4}$ without generation of detectable quantities of $\mathbf{3}$ or $\mathbf{2}$, which established the facility of both $\mathrm{C}-\mathrm{O}$ bond formation and aggregation relative to protodeauration (Scheme 2). Warming this solution to $-30{ }^{\circ} \mathrm{C}$ for $3 \mathrm{~h}$ led to formation of $\mathbf{2}$ in $94 \pm 5 \%$ yield $\left({ }^{1} \mathrm{H}\right.$ NMR) with concomitant regeneration of (L)AuOTs. When a solution of $\mathbf{1}(120 \mathrm{mM})$ and a catalytic amount of (L)AuOTs $(5 \mathrm{~mol} \%)$ in $\mathrm{CD}_{2} \mathrm{Cl}_{2}$ at $-30{ }^{\circ} \mathrm{C}$ was monitored periodically by ${ }^{31} \mathrm{P} \mathrm{NMR}$ spectroscopy, resonances corresponding to $\mathbf{4}$ appeared immediately, persisted throughout $\sim 95 \%$ conversion as the only detectable organometallic species, and then disappeared with regeneration of (L)AuOTs ( $\delta$ 53.5). Kinetic analysis of the gold-catalyzed conversion of $\mathbf{1}$ to 2 under similar conditions revealed a deuterium KIE of $k_{\mathrm{H}} / k_{\mathrm{D}}=5.3$ upon substitution of 1 with $1-O-d(94 \% d) .^{12}$

We likewise investigated the protonolysis behavior of vinyl gold complexes $\mathbf{3}$ and $\mathbf{4}$. Treatment of mono(gold) vinyl species 3 with TsOH ( 2 equiv) at $25^{\circ} \mathrm{C}$ led to immediate ( $₫ 0 \mathrm{~min}$ ) formation of tetrahydrofuran $\mathbf{2}$ in $99 \pm 5 \%$ yield $\left({ }^{1} \mathrm{H}\right.$ NMR; Scheme 2 ). ${ }^{12}$ However, ${ }^{1} \mathrm{H}$ NMR analysis of the reaction of $\mathbf{3}$ with TsOH (1.3 equiv) at $-80{ }^{\circ} \mathrm{C}$ revealed immediate ( $\mathbf{S} \mathrm{min}$ ) retrocyclization/aggregation to form a $\sim 1: 1$ mixture of $\mathbf{1}$ and $\mathbf{4}$ in $>90 \%$ combined yield, along with traces ( $\sim 8 \%$ ) of $\mathbf{2}$ (Scheme 2 ). Warming this solution at $0{ }^{\circ} \mathrm{C}$ for $20 \mathrm{~min}$ led to complete ( $97 \pm 5 \%$ yield by ${ }^{1} \mathrm{H}$ NMR) conversion to 2 and (L)AuOTs

(Scheme 2). Independent kinetic analysis of the reaction of $4(40 \mathrm{mM})$ with HOTs at $5{ }^{\circ} \mathrm{C}$ in $\mathrm{CD}_{2} \mathrm{Cl}_{2}$ revealed $\sim$ zeroth-order dependence on [HOTs] from 38 to $152 \mathrm{mM}$ with no significant deuterium KIE $\left(k_{\mathrm{H}} / k_{\mathrm{D}}=0.9\right)$ for the reaction of 4 with DOTs $(38 \mathrm{mM})$. Both observations point to a mechanism for the conversion of $\mathbf{4}$ to $\mathbf{2}$ involving rate-limiting disproportionation of $\mathbf{4}$ into $\mathbf{3}$ and (L)AuOTs followed by rapid protodeauration of $\mathbf{3}$; however, it must be noted that the concentrations of both $\mathbf{4}$ and HOTs in these experiments exceed those present under catalytic conditions by an order of magnitude.

The experimental observations describe herein and elsewhere ${ }^{7,13}$ support a mechanism for the gold-catalyzed conversion of $\mathbf{1}$ to $\mathbf{2}$ involving rapid and reversible outer-sphere $\mathrm{C}-\mathrm{O}$ bond formation ${ }^{7}$ from the unobserved gold $\pi$-allene complex $\mathbf{I}^{13}$ to form mono(gold) vinyl 
complex 3 with release of HOTs (Scheme 3). Complex 3 undergoes turnover-limiting protodeauration with HOTs to form $\mathbf{2}$ and (L)AuOTs or, alternatively, $\mathbf{3}$ is reversibly sequestered by $(\mathrm{L}) \mathrm{Au}^{+}$to form $\mathbf{4}$ in an off-cycle pathway. All available evidence, notably the large deuterium KIE of catalytic hydroalkoxylation, points to turnover-limiting protodeauration, while the kinetics and KIE of the stoichiometric reaction of 4 with HOTs argues strongly against the direct protonation of $\mathbf{4}$.

With a working mechanism in place, we sought to more fully delineate the interplay between mono(gold) and bis(gold) vinyl complexes during catalysis and to likewise evaluate the reversibility of $\mathrm{C}-\mathrm{O}$ bond formation under catalytic conditions. To this end, we performed a deuterium-labeling experiment that allowed the evolution of bis(gold) vinyl complex 4 to be analyzed independently from on-cycle catalytic turnover. Specifically, an equimolar mixture of $\mathbf{4}$ and HOTs $(1.4 \mathrm{mM})$ was generated in situ from reaction of $\mathbf{1}$ and (L)AuOTs (1:2) at $-78{ }^{\circ} \mathrm{C}$ in $\mathrm{CD}_{2} \mathrm{Cl}_{2}$ (Scheme 4). This solution was treated with excess 1,1dideuterio-2,2-diphenyl-4,5-hexadien-1-ol $\left(\mathbf{1}-d_{2} ; 29 \mathrm{mM}\right)$ at $-78{ }^{\circ} \mathrm{C}$, warmed to $-45^{\circ} \mathrm{C}$, and monitored periodically by ${ }^{1} \mathrm{H}$ NMR spectroscopy (Scheme 4). Plots of [4], [4 + 4- $\left.d_{2}\right]$, [2], and $\left[2+2-d_{2}\right]$ versus time early in the reaction $(2-7 \% \text { conversion })^{14}$ provided initial rate values for the consumption of $\mathbf{4}\left(k_{4}=(-3.8 \pm 0.1) \times 10^{-3} \mathrm{mM} \mathrm{min}^{-1}\right)$ and $\mathbf{4}+\mathbf{4}-d_{2}\left(k_{4 \text { tot }}=\right.$ $\left.(-0.61 \pm 0.02) \times 10^{-3} \mathrm{mM} \mathrm{min}^{-1}\right)$ and for the appearance of $\mathbf{2}\left(k_{2}=(0.74 \pm 0.04) \times 10^{-3}\right.$ $\left.\mathrm{mM} \mathrm{min}^{-1}\right)$ and $\mathbf{2}+\mathbf{2}-d_{2}\left(k_{2 \text { tot }}=(9.1 \pm 0.1) \times 10^{-3} \mathrm{mM} \mathrm{min}^{-1}\right)$ (Figure 2). These data reveal that the rate of total product formation $\left[2-d_{X} ; x=0,2\right]$ was $\sim 2.5$ times greater than was the rate at which 4 was consumed, which, in turn, was $\sim 5$ times greater than the rate of formation of 2 (Figure 2). Two important conclusions were drawn from these observations. First, $\sim 70 \%$ of catalyst turnover bypasses the bis(gold) vinyl complex $4-d_{X}$, which solidifies assignment of $\mathbf{4}$ as an off-cycle catalyst reservoir. Second, $\sim 80 \%$ of mono(gold) vinyl complex 3 generated via disproportionation of protio $\mathbf{4}$ undergoes cycloreversion and ligand exchange rather than protodeauration. ${ }^{15}$ Also worth noting was that over the same conversion range noted above (2-7\%), the total concentration of bis(gold) vinyl isotopomers [4- $\left.d_{X}, X=0,2\right]$ decreased by $\sim 8 \%$, which presumably reflects the approach to the steady-state distribution of (L) $\mathrm{Au}^{+}$between 4- $d_{X}$ and on-cycle mono(gold) complexes (Scheme 3).

In summary, we have elucidated the mechanism of the gold(I)-catalyzed conversion of $\mathbf{1}$ to $\mathbf{2}$, which represents the first mechanistic analysis of gold-catalyzed hydroalkoxylation. The two key conclusions drawn from these studies are that (1) bis(gold) vinyl complex $\mathbf{4}$ is an off-cycle catalyst reservoir and (2) $\mathrm{C}-\mathrm{O}$ bond formation is rapid and reversible under catalytic conditions. The presence of an off-cycle intermediate provides both a target for improving catalytic efficiencies and a rationale for the enhanced reactivity of sterically hindered phosphine and carbene supporting ligands (vis-à-vis $\mathrm{PPh}_{3}$ ) in many gold(I)catalyzed reactions. ${ }^{1}$ Likewise, reversible $\mathrm{C}-\mathrm{O}$ bond formation has important implications regarding stereochemical control in gold(I)-catalyzed enantioselective allene hydrofunctionalization. ${ }^{16}$ Specifically, the result suggests that extant mechanistic models invoking stereochemically determining $\mathrm{C}-\mathrm{Nuc}$ bond formation may require re-evaluation in the context of stereochemically determining protodeauration of an equilibrating mixture of diastereomeric gold vinyl complexes.

\section{Supplementary Material}

Refer to Web version on PubMed Central for supplementary material. 


\section{Acknowledgments}

Financial support is gratefully acknowledged from Duke University for a C. R. Hauser fellowship (T.J.B.), the Fulbright Foreign Student Program (D.W.), the National Institute of General Medicine (GM-60578), and the NSF (CHE-0555425).

\section{REFERENCES}

(1). (a) Bandini M. Chem. Soc. Rev. 2011; 40:1358. [PubMed: 21103507] (b) Corma A, Leyva-Pérez A, Sabater MJ. Chem. Rev. 2011; 111:1657. [PubMed: 21391565] (c) de Mendoza P, Echavarren AM. Pure Appl. Chem. 2010; 82:801.(d) Fürstner A. Chem. Soc. Rev. 2009; 38:3208. [PubMed: 19847352] (e) Rudolph M, Hashmi ASK. Chem. Commun. 2011; 47:6536.(f) Krause N, Winter C. Chem. Rev. 2011; 111:1994. [PubMed: 21314182] (g) Boorman TC, Larrosa I. Chem. Soc. Rev. 2011; 40:1910. [PubMed: 21103517] (h) Pradal A, Toullec PY, Michelet V. Synthesis. 2011:1501.(i) Sengupta S, Shi X. ChemCatChem. 2010; 2:609.

(2). Computational Mechanisms of Au and Pt Catalyzed Reactions. Soriano E, Marco-Contelles J. Topics in Current Chemistry. 2011; Vol. 302SpringerNew York

(3). (a) Liu L-P, Hammond GB. Chem. Soc. Rev. 2012; 41:3129. [PubMed: 22262401] (b) Schmidbaur H, Schier A. Organometallics. 2010; 29:2.(c) Hashmi ASK. Angew. Chem., Int. Ed. 2010; 49:5232.

(4). (a) Liu L-P, Xu B, Mashuta MS, Hammond GB. J. Am. Chem. Soc. 2008; 130:17642. [PubMed: 19055329] (b) Hashmi ASK, Schuster AM, Gaillard S, Cavallo L, Poater A, Nolan SP. Organometallics. 2011; 30:6328.(c) Hashmi ASK, Ramamurthi TD, Rominger F. Adv. Synth. Catal. 2010; 352:971.(d) Chen Y, Wang D, Petersen JL, Akhmedov NG, Shi X. Chem. Commun. 2010; 46:6147.(e) Hashmi ASK, Schuster AM, Rominger F. Angew. Chem., Int. Ed. 2009; 48:8247.

(5). (a) Weber D, Tarselli MA, Gagne MR. Angew. Chem., Int. Ed. 2009; 48:5733.(b) Weber D, Gagné MR. Org. Lett. 2009; 11:4962. [PubMed: 19807117] (c) Seidel G, Lehmann CW, Fürstner A. Angew. Chem., Int. Ed. 2010; 49:8466.(d) Weber D, Jones TD, Adduci LL, Gagné MR. Angew. Chem., Int. Ed. 2012; 51:2452.(e) Hashmi ASK, Braun I, Nösel P, Schädlich J, Wieteck M, Rudolph M, Rominger F. Angew. Chem., Int. Ed. 2012; 51:4456.

(6). Bis(gold) complexes were first proposed on the basis of DFT calculations: Cheong PH, Morganelli P, Luzung MR, Houk KN, Toste FD. J. Am. Chem. Soc. 2008; 130:4517. [PubMed: 18327944]

(7). Zhang Z, Liu C, Kinder RE, Han X, Qian H, Widenhoefer RA. J. Am. Chem. Soc. 2006; 128:9066. [PubMed: 16834380]

(8). Reversible C-Nuc bond formation has not previously been documented for gold-catalyzed allene hydrofunctionalization. Blum has documented the reversible cyclization of an allyl allenoate to form a gold $\sigma$-vinyl allyl oxonium complex, ${ }^{9}$ while Toste has provided evidence for the reversible conversion of a $\gamma$-alkenyl urea to a $\sigma$-alkyl gold complex. ${ }^{10}$

(9). (a) Shi Y, Roth KE, Ramgren SD, Blum SA. J. Am. Chem. Soc. 2009; 131:18022. [PubMed: 19929002] (b) Roth KE, Blum SA. Organometallics. 2010; 29:1712.

(10). LaLonde RL, Brenzovich JWE, Benitez D, Tkatchouk E, Kelley K, Goddard WA, Toste FD. Chem. Sci. 2010; 1:226.

(11). Cyclization of $\mathbf{1}$ catalyzed by either (L)AuOTs ( $5 \mathrm{~mol} \%$ ) in dichloromethane or by a mixture of (L)AuCl/AgOTs in toluene formed $\mathbf{2}$ in $>90 \%$ yield within $5 \mathrm{~min}$ at room temperature.

(12). Both the cyclization of $\mathbf{1}-O-d(\geq 90 \% d$ ) catalyzed by (L)AuOTs and the stoichiometric reaction of 4 with DOTs ( $\geq 90 \%$ d) formed 4,4-diphenyl-2-vinyl(1-deuterio)tetrahydrofuran $\left(2-d_{1}\right)$ with 85 and $79 \%$ deuterium incorporation, respectively.

(13). Brown TJ, Sugie A, Dickens MG, Widenhoefer RA. Organometallics. 2010; 29:4207.

(14). Conversion defined by total product formation $\left(\mathbf{2}+\mathbf{2}-d_{2}\right)$.

(15). Because cycloreversion without ligand exchange $(\mathbf{3} \rightarrow I)$ would not lead to dispersion of $\mathbf{1}$ into the reactant pool, the relative rates of cycloreversion and protodeauration from $\mathbf{3}$ may be significantly greater than the $\sim 4: 1$ ratio determined from this experiment.

(16). (a) Li H, Lee SD, Widenhoefer RA. J. Organomet. Chem. 2011; 696:316. [PubMed: 21909160] (b) LaLonde RL, Wang ZJ, Mba M, Lackner AD, Toste FD. Angew. Chem., Int. Ed. 2010; 
49:598.(c) Zhang Z, Bender CF, Widenhoefer RA. Org. Lett. 2007; 9:2887. [PubMed: 17595096] (d) Zhang Z, Bender CF, Widenhoefer RA. J. Am. Chem. Soc. 2007; 129:14148. [PubMed: 17967025] (e) LaLonde RL, Sherry BD, Kang EJ, Toste FD. J. Am. Chem. Soc. 2007; 129:2452. [PubMed: 17290999] (f) Hamilton GL, Kang EJ, Mba M, Toste FD. Science. 2007; 317:496. [PubMed: 17656720] (g) Zhang Z, Widenhoefer RA. Angew. Chem., Int. Ed. 2007; 46:283. 


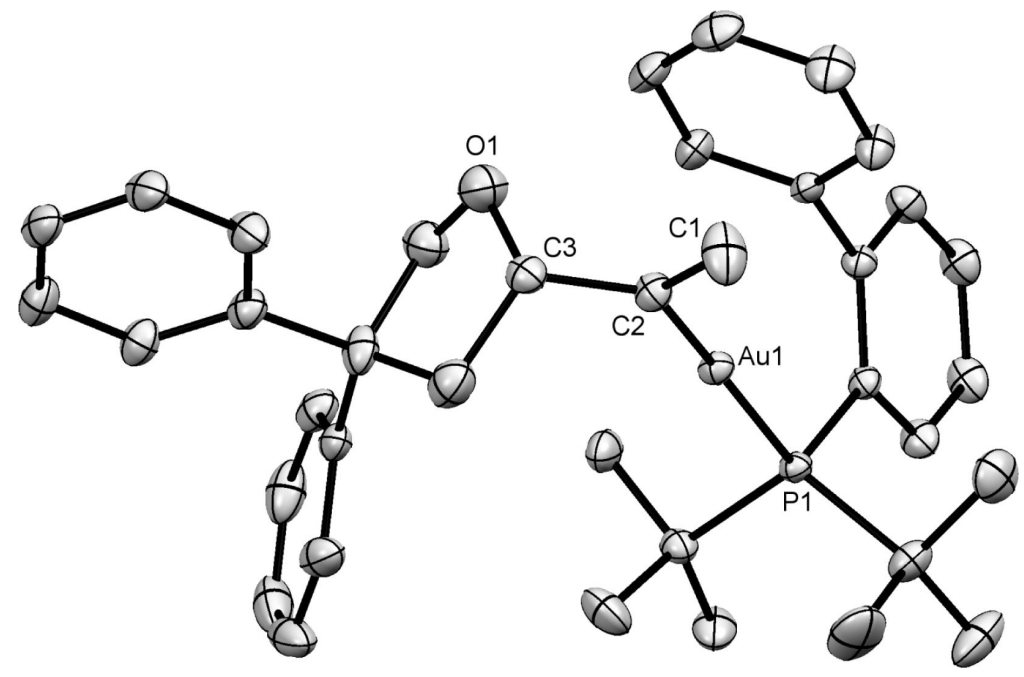

Figure 1.

ORTEP diagram of 3 . Ellipsoids are shown at $50 \%$ probability and hydrogen atoms have been omitted for clarity. Selected bond lengths $(\AA)$ and angles (deg): Au1-C2 $=2.048(7)$, $\mathrm{Au} 1-\mathrm{P} 1=2.3163(16), \mathrm{C} 1-\mathrm{C} 2=1.333(11), \mathrm{C} 2-\mathrm{C} 3=1.518(10), \mathrm{C} 2-\mathrm{Au} 1-\mathrm{P} 1=174.3(2)$, $\mathrm{C} 1-\mathrm{C} 2-\mathrm{Au} 1=120.5(6), \mathrm{C} 3-\mathrm{C} 2-\mathrm{Au} 1=122.4(5), \mathrm{C} 1-\mathrm{C} 2-\mathrm{C} 3=117.0(7)$. 


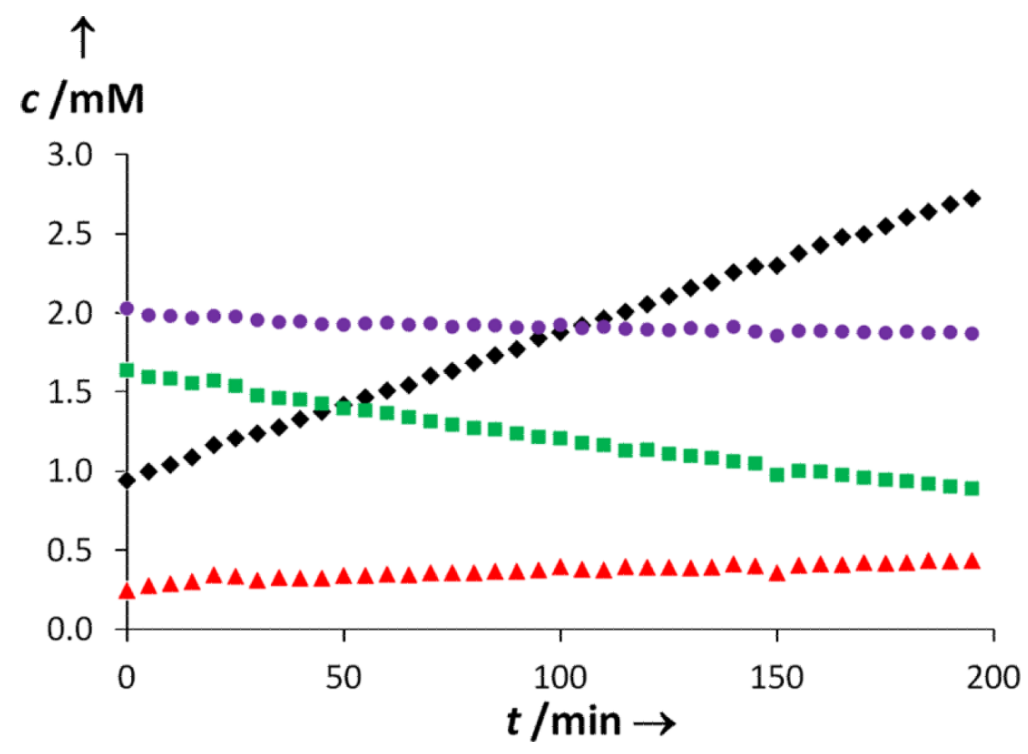

Figure 2.

Concentration versus time plot for the cyclization of $\mathbf{1}-d_{2}(29 \mathrm{mM})$ catalyzed by in situ generated $4(2 \mathrm{mM})$ in $\mathrm{CD}_{2} \mathrm{Cl}_{2}$ at $-45^{\circ} \mathrm{C}$ from $\sim 2 \%$ to $\sim 7 \%$ conversion: [2 $\left.+2-d_{2}\right]$ (black ); [2] (red $\mathbf{\Delta}) ;\left[\mathbf{4}+\mathbf{4}-d_{2}\right]$ (purple $\left.\mathbf{O}\right) ;[\mathbf{4}]$ (green $\left.\mathbf{\square}\right)$. 


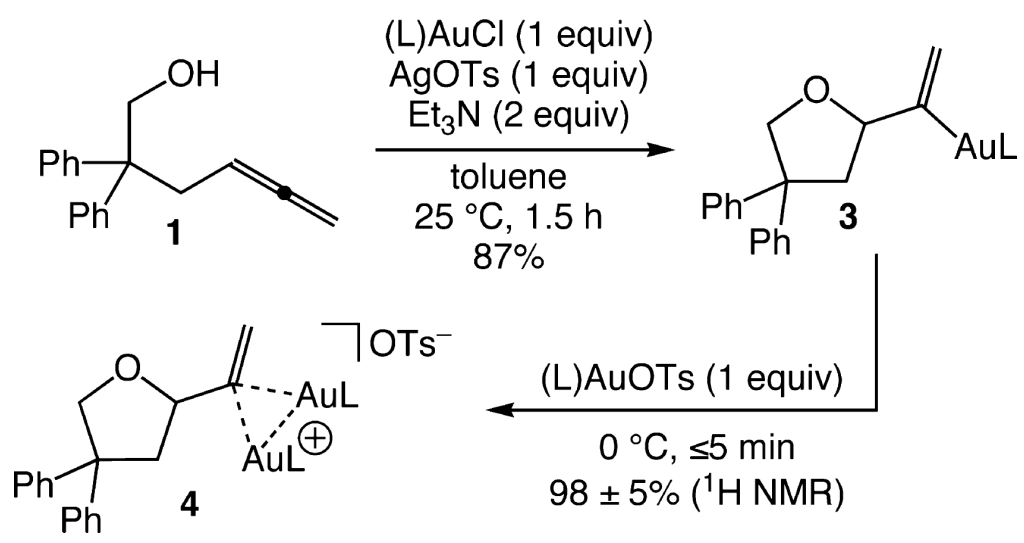

Scheme 1. 

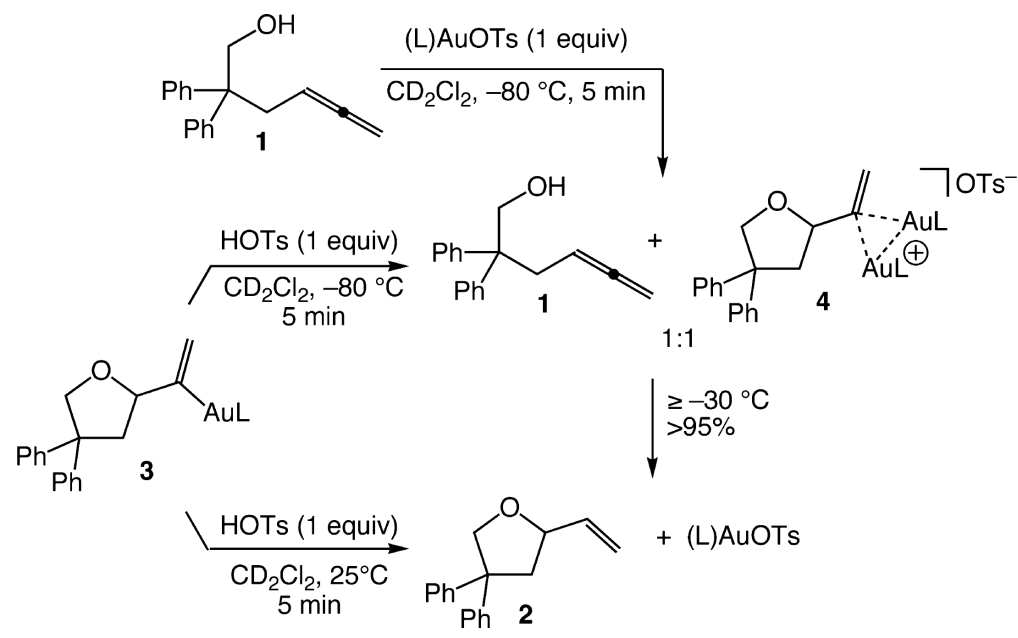

Scheme 2. 

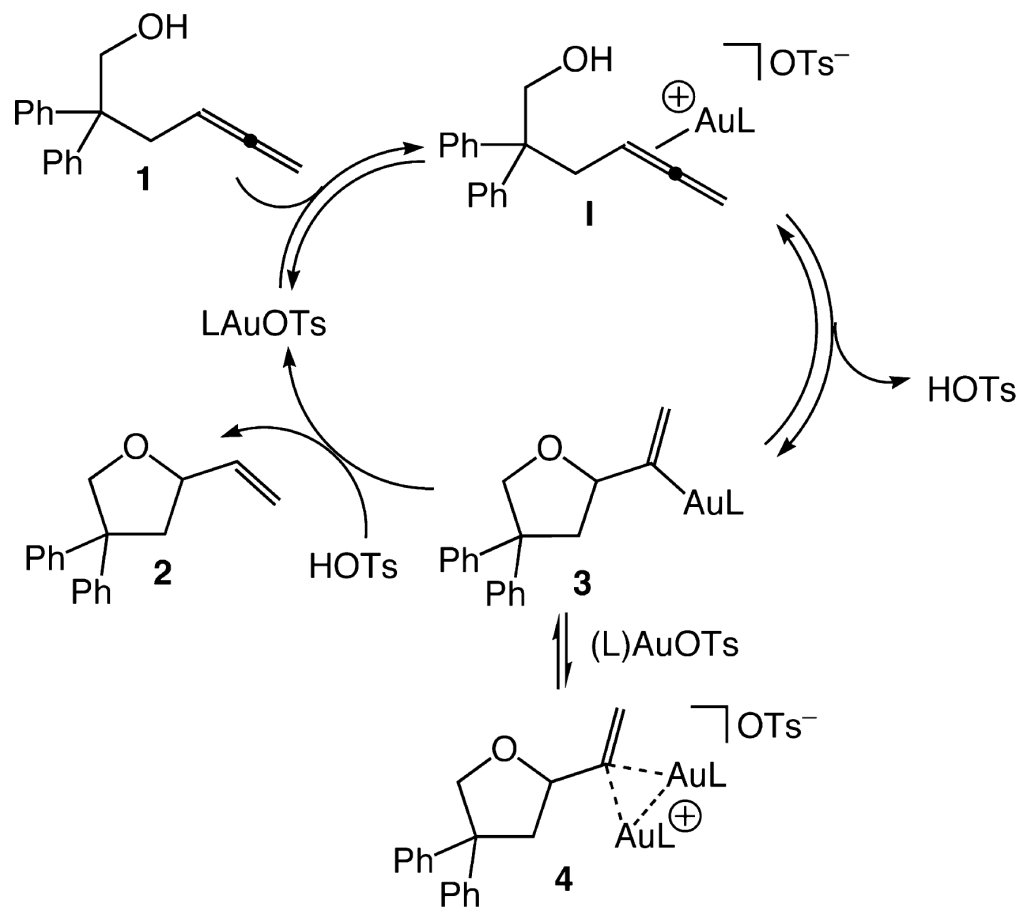

Scheme 3. 

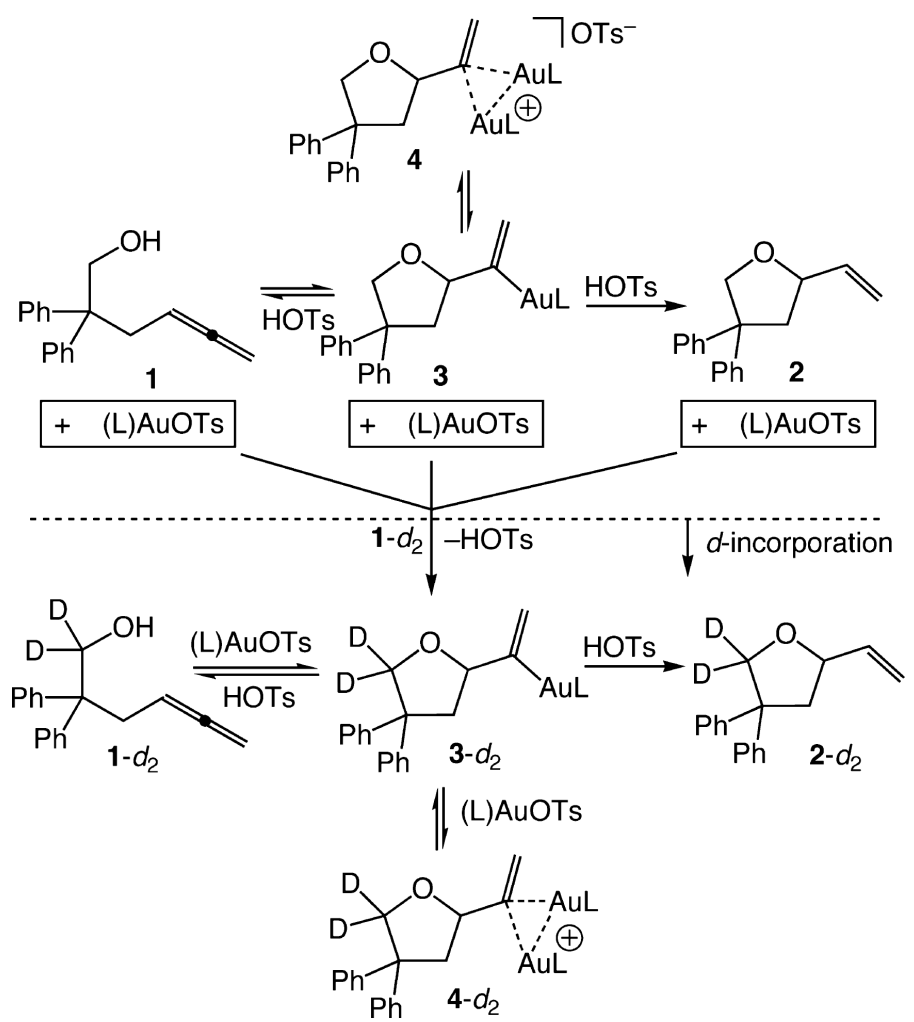

Scheme 4.

Pathways for the Consumption of $4(1.4 \mathrm{mM})$ in the Presence of 1- $d_{2}(29 \mathrm{mM})$ in $\mathrm{CD}_{2} \mathrm{CI}_{2}$ at $-45^{\circ} \mathrm{C}$ 